\section{CURRENT PROGRESS IN PSYCHICAL RESEARCH}

Modern Experiments in Telepathy

By Dr. S. G. Soal and F. Bateman. Pp. $x v+425+$ 3 plates. (London: Faber and Faber, Ltd., 1954.) 30s. net.

A New Approach to Psychical Research

By Antony Flew. Pp. viii +161 . (London : C. A. Watts and Co., Ltd., 1953.) 10s. 6d. net.

Psychical Research Today

By D. J. West. Pp. $144+8$ plates. (London: Gerald Duckworth and Co., Ltd., 1954.) 12s. 6d. net.

THESE three books on modern progress in psychical research are a fair indication of what students are doing and thinking in this hotly debated field. In the first of them, by Dr. S. G. Soal and Mr. F. Bateman, the authors have given us by far the most important work on extra-sensory perception that has hitherto appeared. Not only do they present an admirably documented and critical survey of most of the experimental work in the pesst; but here also will be found in convenient form a full and detailed account of the famous series of card-guessing tests with the two most outstanding British subjects, Mr. Basil Shackleton and Mrs. Gloria Stewart. On reading these records, it is clear that, by their insistence on the most rigid experimental technique, the authors have shown that work in this field can be carried out and brought to fruition as in other branches of science.

Owing to the apparent scarcity of good subjects, much laborious work has to be undertaken with results that, in the end, are wholly without significance. The same precautions, however, have to be observed in every case and the same careful scrutiny of the completed scores. It was only after ten years of such trials that Dr. Soal was fortunate enough to meet his two subjects who, after repeated tests, showed a consistently high rate of scoring which continued after, it would seem, every conceivable precaution had been taken. It is this consistency, coupled with the results of sudden changes in the technique, that makes the theory that extrasensory perception is something of the nature of a statistical artefact very difficult to sustain.

In the early chapters a short survey of the work from 1883 is attempted; but chief attention is rightly given to those series where statistical evaluation of the results was achieved. They show how various sources of error were detected, met and eventually eliminated; how attempts were made to correlate extra-sensory perception with personality ratings, and how Carington's claims for the validity of his results in matching drawings cannot be justified unless an intensive inquiry into common preferences of varied cross-sections of the population has been carried out.

In the present volume, the authors have made but little attempt to discuss their results from the point of view of the psychologist or the philosopher. Such was not their intention. Their aim was to describe and evaluate experimental work, and not to deal with any implications in relation to other fields of inquiry. It is here that Prof. Antony Flew's little book on the connexion between psychical research and philosophy fills the gap. After a brief account of the subject-matter of his thesis, he goes on to discuss the meaning of many of the phenomena reported, and stresses the difficulty of dealing with a subject where so much out-moded terminology abounds. $\mathrm{He}$ believes an approach must be made towards revising these linguistic pitfalls, and that some new terminology should be adopted which is theoretically neutral and not liable to cause so many logical and philosophical perplexities. Believing as he does that extra-sensory perception is a fact, Prof. Flew is at pains to point out that our knowledge of it is so meagre that great care should be exercised lest, by faulty linguistic description, false ideas may be engendered. He maintains, indeed, that almost all the terms in current use are radically unsatisfactory ; and in pointing the way to a new nomenclature he directs the attention of psychologists and philosophers to those phenomena which are more and more engaging the serious consideration of experimenters in this field. How varied are these phenomena and with what caution they have to be treated is set out in concise fashion in Dr. D. J. West's account of psychical research as seen to-day.

It is clear that, in this well-documented and objective survey of the present situation, the author is well acquainted with modern tendencies and the strength and weakness of many of the cases he discusses. Generally speaking, he is inclined to be cautious, and it may come as a surprise to some to find that he regards the evidence for the spontaneous cases such as apparitions as well as various types of veridical hallucinations as far less cogent than has hitherto been supposed.

In his treatment of mental mediumship, the physical phenomena, hauntings and poltergeists, Dr. West is restrained and critical ; and it is only when he treats of progress in work on extra-sensory perception that he shows much enthusiasm. For it is his opinion that, apart from extra-sensory perception and possibly some form of precognition, all is controversy and speculation. In recognizing that extrasensory perception itself cannot be explained upon any physical basis, he joins hands with Prof. Flew in laying stress on the harm that a faulty nomenclature may have on our ideas. As Dr. West concludes, the subject is one big question mark; but he hastens to add that it is remarkable that research has gone so far as it has. For those who wish to become better acquainted with that research, to learn how it is conducted and what may be some of its implications, then these three books are to be recommended. They are some of the most important contributions to the subject that have appeared within the past five years. E. J. Dingwall

\section{MOLECULAR STRUCTURE}

An Advanced Treatise on Physical Chemistry

By Prof. J. R. Partington. Vol. 5 : Molecular Spectra and Structure, Dielectrics and Dipole Moments. Pp. $x+565$. (London: Longmans, Green and Co., Ltd., 1954.) 80s. net.

7 HE latest instalment of Prof. J. R. Partington's

prodigious treatise fills the reader with no less astonishment than did its four predecessors. Anyone who reflects on the enormous effort needed to write what are effectively the two text-books which comprise this particular volume will want to congratulate the author. His lucidity, his breath-taking comprehensiveness and his historical sense, already commented on in reviews of the earlier volumes, are 